IAC-14-D1.3.6

\title{
WICKED PROBLEMS IN SPACE TECHNOLOGY DEVELOPMENT AT NASA
}

\author{
Dr. Tibor Balint \\ Royal College of Art, School of Design, Kensington Gore, London SW7 2EU, United Kingdom \\ tibor.balint@network.rca.ac.uk \\ Dr. John Stevens \\ Royal College of Art, School of Design, Kensington Gore, London SW7 2EU, United Kingdom \\ john.stevens@rca.ac.uk
}

Technological innovation is key to enable future space exploration missions. Technology development, however, is not only driven by performance and resource considerations, but also by a broad range of directly or loosely interconnected factors. These include, among others, strategy, policy and politics at various levels, tactics and programmatics, interactions between stakeholders, resource requirements, performance goals from component to system level, mission infusion targets, portfolio execution and tracking, and technology push or mission pull. Furthermore, these influences occur on varying timescales and at diverse geographic locations. Such a complex and interconnected system could impede space technology innovation in the government environment. Hence, understanding the process through the Planning, Programming, Budget and Execution cycle could benefit strategic thinking, planning and execution. Insights could be gained through suitable models, for example assessing the key drivers against the framework of Wicked Problems. This paper discusses space technology innovation and innovation barriers in the government environment through the characteristics of Wicked Problems; that is, they do not have right or wrong solutions, only improved outcomes that can be reached through authoritative, competitive, or collaborative means. We will also augment the Wicked Problems model to account for the temporally and spatially coupled, and cyclical nature of this specific case, and propose how appropriate models could improve understanding of the key influencing factors and lead to reducing innovation barriers, subsequently stimulating technology innovation at NASA and other government-directed environments.

\section{INTRODUCTION}

Over the past 30 years in the US, more than 40 studies pointed to a need for regular investments into new, transformative space technologies within NASA. These technologies are required to enable new class of NASA missions beyond Low Earth Orbit (LEO) and to provide innovative solutions to dramatically improve technological capabilities for NASA and for the United States. There are a number of drivers associated with this recommendation. For example, the development of such technologies need to be affordable and reliable for space exploration. Government funded innovation activities are expected to span across the full scale of Technology Readiness Levels (TRL), starting at fundamental research and early stage innovation. At the fundamental research level the Agency needs to engage the brightest minds from academia to solve the difficult technology challenges faced by NASA's space exploration missions. Furthermore, these technology development activities can be used to create new markets, while stimulating innovation for traditional and emerging aerospace businesses [NASA-STMD, 2014].

To understand the drivers influencing technology development, we need to look beyond performance and resource considerations, and examine a broader range of directly or loosely interconnected factors both inside and outside of NASA. These include, among others, strategy, policy and politics at various levels, tactics and programmatics, interactions between stakeholders, resource requirements, performance goals from component to system level, mission infusion targets, portfolio execution and tracking, and technology push or mission pull. In addition, the process and influencing factors for this dynamic system occur on varying timescales and at diverse geographic locations. Many of these factors are accounted for in the Planning, Programming, Budget and Execution (PPBE) process, which will be briefly discussed in our paper.

The PPBE process is on the planning and execution side of the operations, and if not driven, influenced and supported by appropriate strategies, then such a complex and interconnected system could impede space technology innovation in the government environment. A good strategic approach includes three key elements: a diagnosis, a guiding policy, and a set of coherent actions. [Rumelt, 2011]. This paper contributes to the diagnosis part, by describing the technology development related interactions and influences between NASA and relevant external entities. Subsequently, these interfaces and related constraints will be discussed using the Wicked Problems model [Rittel \& Webber, 1973]. In general, models are created through the reduction of complex systems to simple ones [Weinberg, 1991], and as George E.P. Box pointed it out, "essentially, all models are wrong, but some are useful" [Box \& Draper, 1987]. Therefore, to draw meaningful conclusions from models, the simplifications have to capture and weight all the key 
influencing factors, and ignore those which have secondary effects on the modeled system. Such modeling is not trivial. As stated by Laurence J. Peter [Peter, 1982], "some problems are so complex that you have to be highly intelligent and well informed just to be undecided about them." We hope that our simplifications will capture key elements of these complexities facing technology development activities, drivers and influences at NASA, and will help to elucidate the implementation challenges at hand.

We will show that the Wicked Problems model is providing a reasonable framework for the case of NASA's technology development activities. These problems do not have right or wrong solutions, only improved outcomes that can be reached through authoritative, competitive, or collaborative means. With appropriate strategies these problems could solve or at least reduce technology development barriers. To this end, we will further customize the model with additional rules to strengthen the construct for this particular case. Specifically, we will augment the Wicked Problems model to account for the temporally and spatially coupled, and cyclical nature of this case, to promote a better understanding, and subsequently stimulate technology innovation at NASA and other government-directed environments.

\section{I.I Wicked Problems}

The phrase "wicked problem" was first used in social planning to describe a problem, which does not have an obvious solution, due to changing requirements, and incomplete or contradictory bounding conditions. Furthermore, as a result of the often complex interdependencies, a chosen solution to a wicked problem could result in subsequent new problems. Rittel and Webber introduced 10 general rules to describe Wicked Problems [Rittel \& Webber, 1973], which was synthesized and reduced to 6 general characteristics by Conklin [Conklin, 2006]. These are:

1. The problem is not understood until after the formulation of a solution;

2. Wicked problems have no stopping rules, difficult to know when the problem is solved or solution is reached;

3. Solutions to wicked problems are not right or wrong;

4. Every wicked problem is essentially novel and unique;

5. Every solution to a wicked problem is a "one shot operation";

6. Wicked problems have no given alternative solutions.

Wicked Problems are not simply too hard or complex, nor require additional considerations or have more stakeholders. In addition, the initial problem definition and the outcome are bi-directionally linked. The various stakeholders may have radically different perspectives, motivations, and drivers related to the issues. Therefore, the assessment of an optimal outcome is dependent on the perspective of the stakeholder, instead of considering it universally right. Because the initial problems and the related resource requirements are often ill defined, they are typically over-constrained, can't be solved definitively through analytical thinking, and may require innovative solutions.

Roberts identified three strategies to tackle wicked problems [Roberts, 2000]. Implementation of these strategies are influenced by management styles and institutional approaches. These are:

1. Authoritative: This strategy places responsibility of solving problems to one or a few people. This is perceived to reduce the complexity of perspectives as competing views are being eliminated. The disadvantage is that key perspectives might be eliminated, or not appreciated, which may lead to less favorable outcomes.

2. Competitive: This strategy brings opposing views against each other. It requires stakeholders to hold their views and propose their preferred solutions, so the different solutions could be compared and weighted. The disadvantage is the potential of creating confrontations and discouraging knowledge exchange. In turn this may disincentivize the stakeholders to propose solutions.

3. Collaborative: This strategy involves all stakeholders working and converge towards a common best solution, agreed upon by all parties involved.

NASA operates in a framework with a broad variety of stakeholders, where the associated problems and challenges go beyond a strictly rational, scientific and technical approach. As shown in Figure 1, NASA's stakeholders range from the top branches of the US Government to the project execution level both inside and outside of NASA, resulting in diverse perspectives, interests, and influences.

I.II Design Thinking as Integrative Systems Thinking

Space exploration introduces significant technological challenges, where incremental developments can fulfill near term needs, but future missions will require new alternatives and new ideas. Existing solutions are becoming obsolete and design thinking could provide a new approach to tackle these emerging problems. Design today is often viewed as a discipline focusing on aesthetics, image, and fashion. However, design accounts for more then simple ergonomics and packaging. Therefore, we should focus less on the resulting artifacts and more on the approach to achieve the desired goal. This design thinking approach allows us to address challenges through transformational innovations. Design thinking begins with integrative thinking to exploit opposing ideas and opposing constraints, and to create new solutions. In the case of design that means balancing desirability (what humans need), (technical) feasibility, and (economic) 


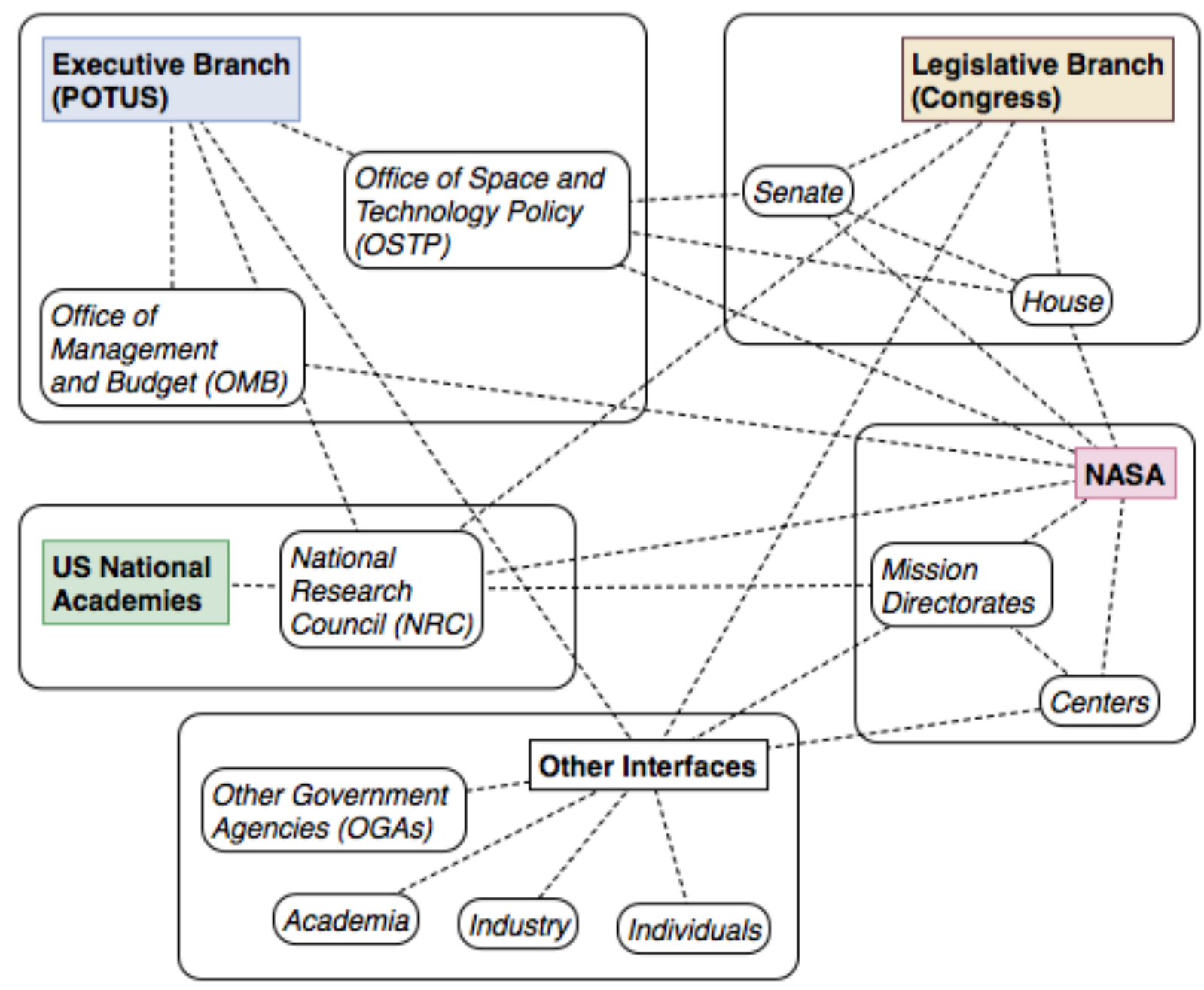

Fig. 1: Links between NASA and its stakeholders

viability [Martin, 2009]. The design and creation of new artifacts and processes can benefit from design thinking and systems thinking, through a combination of observational research, brainstorming for new solutions, and rapid prototyping. This strategy starts with a human centered approach (usability), while also integrating technology (feasibility) and economics (viability) [Balint, 2013]. Design thinking also looks at a broad range of considerations, including the understanding of culture, aspirations, motivations and context, at every level contributing to the framework. This approach can be beneficial to derive strategies in the government framework, where multiple stakeholders have diverse sets of drivers and expectations.

Design thinking requires learning by making, and building in order to think. In effect, it often builds on tacit knowledge [Polanyi, 2009], which uses prototypes to speed up the process of innovation, because creating them will allow the practitioner to understand the strengths and weaknesses of the artifact or the process being designed. Faster turnaround results in faster evolution of ideas, which can result in better outcomes while saving resources. Socializing prototypes also results in an inclusion of stakeholders at an early stage, and encourage feedback for faster iteration, acceptance, and dispersion of the new technology. This is in line with the collaborative approach of solving wicked problems.

Design thinking is important for the development of transformational technologies. Instead of the current linear way of making the best choice out of available alternatives, it encourages us to take a divergent approach, create new options, explore new alternatives, find new solutions and new ideas, that didn't exist before. The process and use of divergence and convergence cycles, and their application for technology development at NASA are discussed in [Balint, 2013].

Good design, may it be a process, an artifact, or service, can provide distinct advantages over purely technology driven developments, because of its multi- 


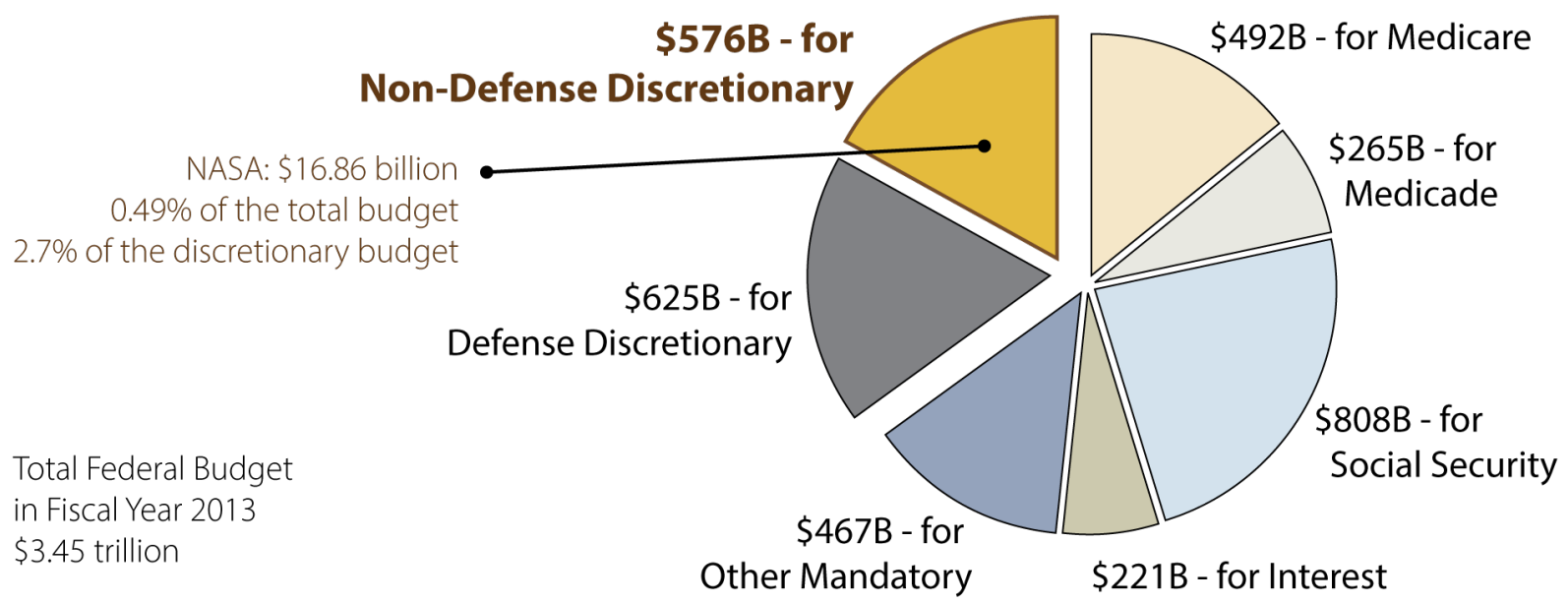

Fig. 2: Federal budget breakdown for Fiscal Year 2013 [HoR, 2014]

disciplinary nature. Its transformative characteristics involve four major elements [Norman \& Klemmner, 2014], namely:

- Design Thinking: to identify and solve the right problem;

- Systems Thinking: to account for the crosscutting multiple disciplines;

- Integrative: where both design theory and practice are accounted for; and

- Human-Centered Design: to assure harmonious synergies between the user and technology.

\section{NASA IN THE GOVERNMENT FRAMEWORK}

Technology development at NASA is influenced by a broad range of factors, beyond Agency needs, technical performance, project and program resource requirements. In oder to demonstrate why we consider technology development at NASA a wicked problem, we need a better understanding of the budget breakdown, the budgetary process, and influencing drivers within this broader framework.

\section{II.I NASA's Budget}

NASA's annual budget is part of the United States federal budget, which funds government operations for a given fiscal year. The U.S. Government Budget begins as the President's Budget Request (PBR) from the Executive Branch, to the U.S. Congress under the Legislative Branch. In the PBR, the President recommends funding levels for the next fiscal year. The fiscal year begins on October 1, and ends on September 30 of the following year. The PBR is not the final budget for the government agencies. By law, the budget is appropriated by Congress on an annual basis. Congressional decisions are set by budget committees, identifying spending limits, which are subsequently approved by appropriation subcommittees to allocate funding to the various federal agencies and programs.
The funding bill is then passed by both the House of Senate and the House of Representatives of the Congress, and sent to the President of the United States (POTUS) for signature. In this paper we give a notional and simplified explanation of the process, as the appropriation bill may come in other formats, including an omnibus spending bill, a continuing resolution (CR), or a supplemental appropriation bill. It can also be impacted by other spending measures, such as the sequestration process. Further details on the NASA relevant budgeting process is discussed in the following sub-section, describing the Programing, Planning, Budget and Execution (PPBE) process.

However, it is important to relate the size of NASA's budget to the overall federal budget, as it provides an indication on the perceived importance and relevance of this government agency compared to other entities. We will demonstrate this through the U.S. Federal Budget breakdown from the Fiscal Year (FY) 2013 [HoR, 2014], shown in Figure 2. The total spending amounted to $\$ 3.45$ trillion, which included mandatory and discretionally spending elements. Spending for mandatory programs cannot be reduced, and it includes paying the interest on the national deficit, and covers the major entitlement programs, such as medicare, medicaid, and social security. Discretionary spending can theoretically reduced to zero by Congress, based on Constitutional law. It includes both defense and nondefense related spending. NASA falls under the nondefense related spending category and its budget can fluctuate year after year. In FY2013 NASA's appropriated budget was $\$ 16.865$ billion, which is $2.7 \%$ of the non-defense based discretionary funding, and $0.49 \%$ of the total federal budget. In comparison, during that Apollo era, NASA's budget amounted to about $4.4 \%$ of the national budget, which was about 9 times higher than the current level.

Further breakdown of NASA's FY2013 budget shows a mixed distribution between the 4 mission 


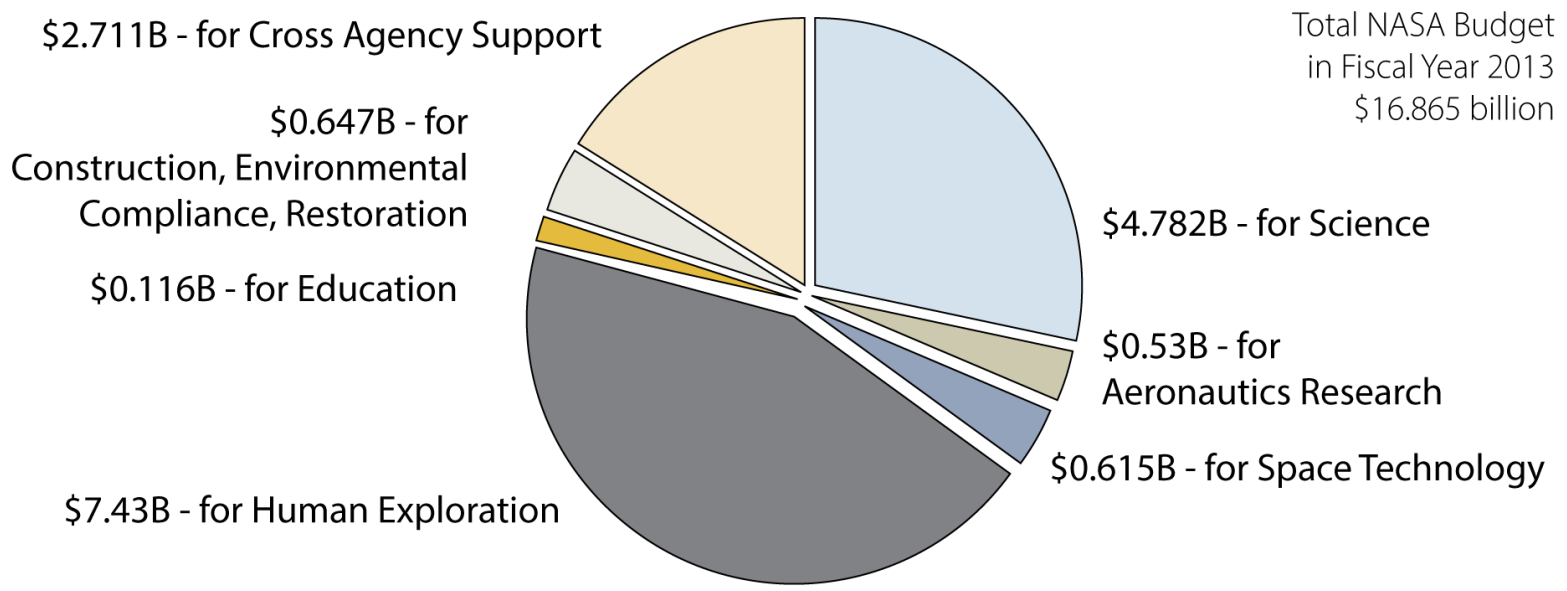

Fig. 3: NASA internal budget breakdown for Fiscal Year 2013 [NASA, 2014]

directorates [NASA, 2014] - see Figure 3. The enacted budget for the Science was $\$ 4.782 \mathrm{~B}$; for Aeronautics Research \$530M; for Space Technology \$615M; for Human Exploration \$7.43B; with further allocation for Education $(\$ 116 \mathrm{M})$; Construction and Environmental Compliance and Restoration $(\$ 647 \mathrm{M})$; and Cross Agency Support for NASA-wide management and operations support (\$2.711B). While these numbers may look reasonably large compared to other national space agencies, the allocations are further divided by Mission Directorate Divisions, Programs and Projects. The appropriated budget includes a large number of mandatory spending allocations as well, for example, funding continuing development of the Orion MultiPurpose Crew Vehicle, Space Launch System (SLS), and the Exploration Ground Systems (EGS) under Human Exploration, or the James Webb Space Telescope under Science. Additional details on the budget breakdown is provided in [NASA, 2014].

The main purpose of the above discussion was to demonstrate the complexities and constraints associated with NASA's budget, and to illustrate how budget uncertainties could have a significant impact on the initial science, exploration and technology plans.

\section{II.II PPBE Process}

NASA's annual budget is part of the U.S. Federal budget and negotiated through the Planning, Programing, Budget and Execution (PPBE) process, which focuses on financial management and resource allocation for current and future acquisition programs. While the budget is set for a given fiscal year, the PPBE process bridges an approximately 3 years fiscal time period.

The PPBE process consists of four distinct phases, which are carried out in parallel. These are:

- Planning: this phase is designed to define content and examine alternative strategies, analyze trends and changing conditions, needs for new technologies, threats, and to provide an economic assessment of potential outcomes from new options, and projected long-term outcomes of current choices. If not done correctly, it may revert to a simple forward projection of current activities, leaving out the strategic assessment of alternatives. While on a short term this latter approach may indicate a firm direction, on the longer term it can harm the organization.

- Programming: this phase connects the planning elements with their multi-year resource implications, and evaluates various tradeoff options. When planning and programming are performed concurrently, with a focus on forward planning only, there is a danger of describing a broader yet linearly projected future, instead of providing trades and alternatives.

- Budgeting: this phase addresses the formulation, justification, execution, and control of the budget for the following year. It is formulated to align with both national and Agency needs and requirements to achieve the set out plans.

- Execution: this phase represents the actual implementation of the process, where the budget is spent in the current fiscal year, according to plans defined through the previous phases. In a typical PPBE cycle the budget is appropriated on time at the beginning of the fiscal year, and the program is executed accordingly. However, appropriation delays and other factors may result in resource allocation changes throughout the year, which could introduce budget uncertainties, focus creep, and may negatively impact the planned execution.

The idealized PPBE process is shown in Figure 4. Idealized, because it assumes a predictable theoretical cadence of the steps and actions. In practice a number of uncertainties can have significant impacts on carrying out this plan. For example, reoccurring delays related to annual budget appropriations result in so called 

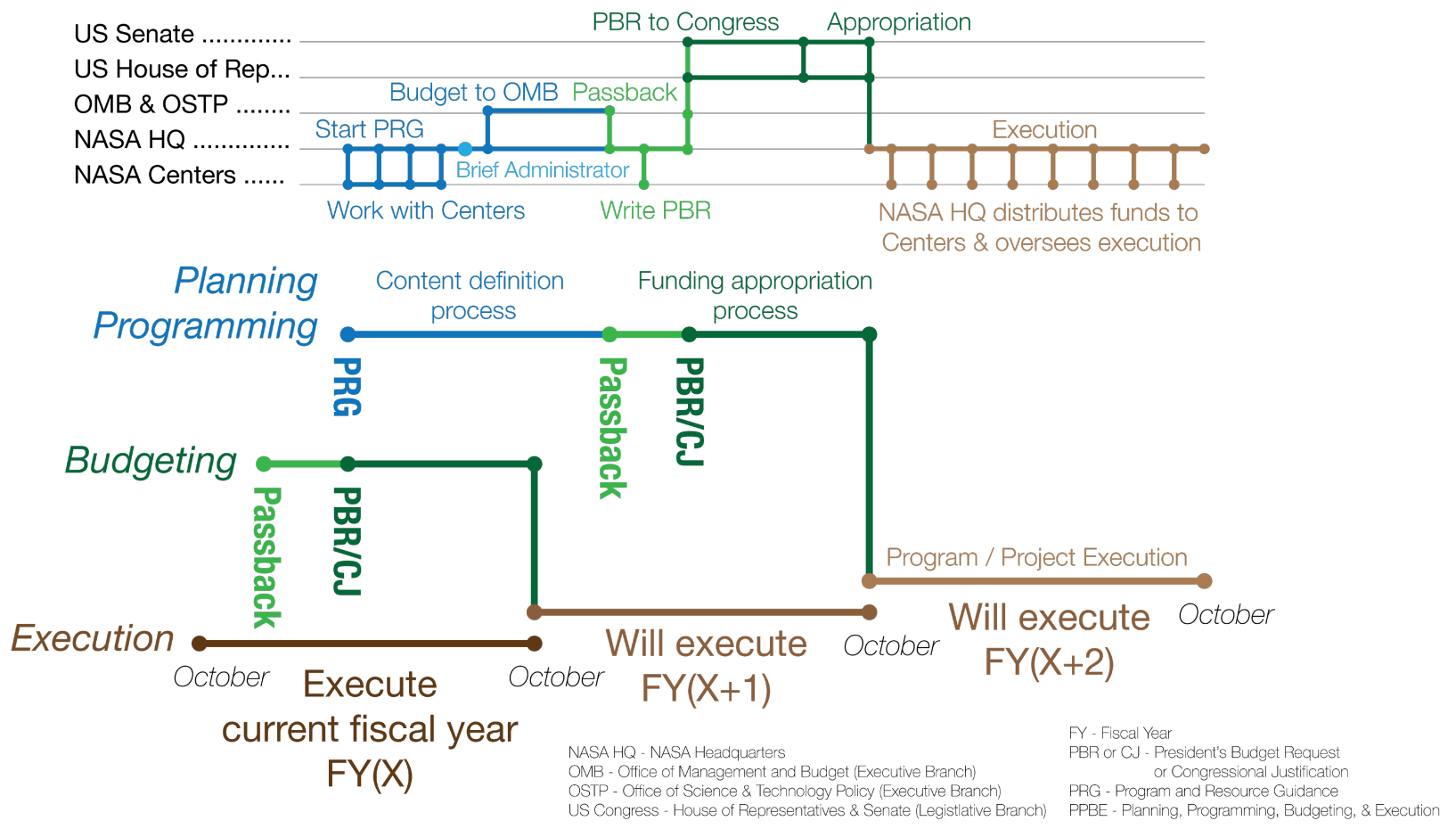

Fig. 4: Notional PPBE process for NASA

continuing resolutions (CR), which may take from months to even a full fiscal year to resolve. In turn, CR has an impact on funding and resource allocation, project execution, descopes, delays, and even new content initiation in a given fiscal year.

Planning and programming is performed through interfaces between three key stakeholders. The activity is led by NASA HQ as a focal point, first interacting with NASA centers regarding resource allocation plans and needs in support of the planned content, and following a briefing to the NASA Administrator, the budget and related content plans are sent to the Government's Executive Branch for assessment against national funding plans, strategies and policy alignments. This process starts about a year and a half in advance of budget appropriation. This phase completes with the "Passback" step, where the Office of Management and Budget (OMB) under the Executive Branch provides actionable feedback on the submitted plans. It occurs less than a year before budget appropriation. In addition to OMB, NASA is also coordinating with the Office of Science and Technology Policy (OSTP) under the Executive Branch, to align with national strategies and policies.

The budgeting phase involves three stakeholders. NASA, and both the Executive and Legislative Branches of the US Government. After receiving the "Passback" from OMB, NASA HQ makes the necessary adjustments to the plan, and compiles the President's Budget Request (PBR) document, which is also called Congressional Justification (CJ). The updates are made following discussions with the NASA Centers, in order to optimize - within constraints identified in the "Passback" - for common goals and targeted outcomes. The PBR document is sent to Congress in the middle of the fiscal year. Within Congress, four entities are set to assess the PBR document, namely the authorization and appropriation sides of the Senate and the House of Representatives. The budget - to be appropriated requires an agreement between the Senate and the House of Representatives before signed by the President and passed into law.

Once appropriated, NASA receives the budget with markups from the Congress, and proceeds with the execution. This markup often includes earmarks and other changes, in addition to modifications to the final budget, which is often lower than recommended in the PBR. This can result in a flurry of re-planning activities within NASA, including the assessment of the impacts on various projects, and modifications to the milestones and deliverables. The mismatch between the PBR plans and the appropriated budget plans translates to changes to the programs and projects, which may vary from minor impacts to significant or complete redirections. If the budget is not appropriated on time, which has been the case for most years over the past decade, then the projects are forced to execute under the assumption of the previous year's budget allocation. If the subsequent appropriated budget is lower than that for the previous year, projects can be significantly impacted and often harmed for the rest of the fiscal year and beyond. 
The PPBE process is cyclical, with annual cycles and associated uncertainties. Consequently, planning and execution is often becomes a challenging exercise, putting significant pressure on all of the parties involved, from the Mission Directorate level at NASA HQ down to the project execution level. In this domino effect, project resource changes can also propagate to external contractors, thus impacting space related industries, small companies, and academic institutions.

\section{II.III Influencing Drivers}

Technology development and related innovation at NASA are influenced by both direct and indirect drivers. This includes the highest branches of the US federal government, NASA's organizational structure from Headquarters to NASA Centers, and external entities from the National Research Council, to academia, industry, and Other Government Agencies (OGA). We are discussing the influencing elements from a top down hierarchy, shown in Figure 1. Many of the influencing factors listed here are further detailed in [Balint, 2013].

\section{II.III.I US Federal Government}

At the highest level, two branches of the US government are involved, namely the Executive and Legislative branches. The third, Judicial branch, does not have an active role on the day to day activities of NASA. The Executive Branch under the President of the United States (POTUS) has two offices which are working with NASA on the budgetary process and setting strategic directions. The former is the Office of Management and Budget (OMB), where the Science and Space Branch is embedded in the fourth level under the Resource Management Offices, the National Resource Programs, and the Energy Science and Water Division. Similarly, for the latter one, for the Space and Aeronautics Branch is positioned under the Advisors of Policy, then the Office of Science and Technology Policy (OSTP), and Technology and Innovation Division. OMB is concerned with the planning of the overall annual national budget, where NASA's budget is below $0.5 \%$ (compared to the $4.4 \%$ during the Apollo era). Its perceived importance at this level is often aligned with the allocated budget. OSTP is driven by national level interests, where STEM (Science, Technology, Engineering and Mathematics) education, national and international prestige and leadership are important factors. One possible way to achieve some of the national goals are through space exploration, but it is not the only path. NASA's alignment with national initiatives, for example with the National Robotic Initiative, Material Genomes Initiative, National Nanotechnology Initiative, and Manufacturing Innovation are also important drivers. Consequently, the considerations about NASA's importance within the overall national level strategic and political framework and related resource allocation portion from the national budget are weighted accordingly. The 4-year presidential election cycle also influences presidential priorities and related decision making, primarily focusing on other higher priority national interest from health care to national security, thus keeping decisions related to NASA on a flat and continuous trajectory. Regularly pointing to the fact that NASA's budget is still higher than that of the combined budget other national space agencies, and the politically driven space race is over, the drivers to increase the budget are not strong. Still, the annual President's Budget Request shows an increasing budget trend, which typically does not materialize during the appropriation process by Congress. The Legislative Branch is represented by the Congress, and includes the Senate, with two senators per state, and the House of Representatives with one representative for every 13,000 people. Both has their authorization and appropriation committees, responsible for advancing the PPBE process, and appropriating the budget. Within the Congress the drivers are often different from those for OMB and OSTP. Priorities include resource allocation to specific states, championed by state representatives on appropriation committees. Related earmarks in the appropriated budget often identify specific high budget projects, linked to specific states, thus creating jobs and stimulating local economies. Earmarks, combined with budget cuts, frequently overwrite the set directions described in the President's Budget Request, and constrain NASA's ability to allocate resources and start new projects recommended by the nation's leading scientists and technologists. At times the Executive and Legislative Branches, and within the Congress the Senate and the House of Representative align, and at other times seem to act as obstructionists. These dynamics can also have an impact on the budget appropriation outcomes. Furthermore, NASA's annual budget is effected by multiple overlapping temporal and spatial cycles, related to elections and the regional impact of changing representatives on committees, influencing budget appropriation.

\section{II.III.II National Research Council}

Recommendations for exploration target through either human or robotic exploration are supported by studies by the National Research Council. These studies are used by NASA as guiding documents. The NRC is an independent body, bringing together the Nation's most respected scientists, engineers, technologists and researchers. Through decadal surveys, technology roadmap studies, and targeted reports, the NRC provides guidance to NASA on priorities about future missions and technology development needs. These are used by NASA during the PPBE phases, when discussing future strategic content both within the Agency and with the government. The NRC also provides independent direct input to the government's side during these budgetary negotiations. 


\section{II.III.III NASA}

Agency level strategic and programmatic coordinations and oversight at the ten NASA Centers are performed from NASA Headquarters. In effect, the role of NASA HQ is to provide the primary interface between the Government and the Centers, plan, prepare, and negotiate NASA's annual budget (with inputs from the Centers on workforce and resource allocation needs), and subsequently distribute appropriate resources to the performers. HQ is also responsible for Agency and Mission Directorate level (Level 1) strategic decision making, execution oversight, setting and enforcing procedural requirements, portfolio assessment, balancing and planning based on strategic considerations, oversight of roadmapping and design reference mission planning activities, communications, and interfacing with stakeholders inside and outside of NASA. Collaboration and alignment between the four Mission Directorates is coordinated at the HQ level. External stakeholders, from industry, academia, and other government agencies are approached to discuss strategic collaborations and future project ideas. International collaboration is desired, but ITAR regulations can make the arrangement non-trivial. HQ also runs solicitations through a competitive process, or authoritatively directs projects to performers. Beside the procedural influences, organizational structures can impact operating modes and outcomes, and we can't expect different results and efficiencies from organizations if the setups are identical. As stated by Marshall McLuhan, "we become what we behold," that "we shape our tools, and thereafter our tools shape us." Personalities at every level play important roles at workplaces. Leadership styles could vary from collaborative to authoritative, and skills can differ greatly, influencing workplace dynamics, program and project outcomes, and the overall success of the organization. Typically NASA Centers house the Level 2 Program Offices. These offices are the interface between Level 1 and the Projects at Level 3. Centers work within their own organizational structures, managing their workforce and active project, which is often challenging due to budget uncertainties. Replanning at the program and project level is a frequent activity, with impacts to project execution and deliverables. Budget uncertainties and reduction can introduce stress points between the various centers with somewhat overlapping capabilities, competing for the same funding. The geographic distribution of the ten NASA Centers can introduce complexities to collaborations on distributed project.

\section{II.III.IV Other Government Agencies}

Just like NASA, all government agencies receive funding from the federal government on an annual basis. Over the years, funding for most agencies were stagnant, stimulating collaborations on various projects, when the core competences and project goals sufficiently aligned. In a shrinking budgetary environment these consolidations can provide short term success, but gradually making them not viable. "You can’t shrink your way to greatness." [Peters, 1997]

\section{II.III.V Academia}

The primary product of universities is knowledge, which is transmitted to the stakeholders. They are well suited for early stage technology development through grants and other types of awards. Ensuring funding continuation through budget uncertainties could represents challenges for NASA.

\section{II.III.VI Industry}

NASA works with the industrial base, ranging from small to large companies with strong funding dependencies from the government. Aerospace companies, focusing on space related technology development can be impacted by limited and uncertain budget appropriations. Maintaining core competence at these companies can be important for the future of the Agency, but decreasing or stagnant budgets could reduce the number of solicitations for new technologies, and the number of awards to be handed out. Further complications for NASA can rise when dissatisfied companies attempt to force alternative approaches, by appealing to their congressional representatives in support of leveraging a more favorable response from the Agency.

From the long list it is clear that the number of influencing factors impacting technology development at NASA range well beyond a purely technological feasibility, resource related viability, and Agency or national needs.

\section{DISCUSSIONS}

A better understanding of the complexities discussed above allows us to make well informed strategic decisions.

III.I Why is this a wicked problem?

Looking at the six characteristics of wicked problems [Conklin, 2006] (and referring to them as WPC1 to 6), we find the following.

- WPC1: For NASA - and for all government agencies - the annual budget is unknown until it is appropriated. The appropriation at the beginning of the fiscal year is far from certain, and can stretch through the full fiscal year. Regularly included earmarks and changing content from the PBR introduce further uncertainties. Once the appropriation is done, NASA HQ updates the plans and allocates resources in the best suitable way.

- WPC2: Project may encounter difficulties due to changing resource allocations, and further interventions are needed to resolve these issues.

- WPC3: Operating in a resource limited environment, strategic decisions are needed on a 
number of issues, focusing on subsets of the problem, which can be addressed under the circumstances. For example, program execution can target short or long term technology needs, incremental or transformational technology developments, or a mixture of them. Any of these approaches can be justified and may lead to success or failure as propagated to the future.

- WPC4: NASA's technology portfolio is changing continuously, with projects being completed and new projects starting. Program resources are influenced by budget allocation uncertainties year after year. While past experiences may help to resolve these issues, every year a new set of variables are introduced, making the problems at hand always novel and unique.

- WPC5: Once the budget is appropriated, NASA HQ responds to allocate the needed resources to the performers. This has to be done swiftly to limit negative impacts to the programs and projects. Once the resources are allocated, the projects are responsible to perform at the expected level. Pushing technology boundaries can result in project overruns, requiring additional resources at any time of the year, complicating the process and introducing stress points.

- WPC6: NASA's resources are constrained and uncertain within bounds. Project risks can be mitigated through reserves to a point, but the continuous interplay between the full portfolio of projects and their uncertainties, constrained by a limited budget makes the outcomes unique. Driven by strategic decisions, some project might be impacted more than others, without alternative solutions.

\section{III.II Cyclicality, Temporality, and Spatiality}

Based on the discussions above, we can further refine the Wicked Problems model for NASA, to account for its temporally and spatially coupled cyclical nature. We have identified cyclicality due to the annual budget appropriation cycle, governmental mid-term elections in every two years, and presidential elections every four years. Furthermore, some of the technologies may take a decade to develop, which introduces an additional layer of an even longer timeframe. The annual budget cycle often introduces resource-related uncertainties, driven by appropriated budget levels and time delays. When the budget is not appropriated by the first day of the fiscal year, the Agency operates under Continuing Resolution (CR) guidelines, when new project cannot be started, and spending is held at the level of the previous fiscal year. An extended length of the CR (and other compounding factors, such as sequestration) may also lead to continuous re-planning cycles, resource reduction to the projects, or at times to rush spending at the end of the fiscal year. In addition, appropriated budgets are frequently lower from the PBR amount, requiring further re-planning activities. The national election cycles contribute to the temporality of the Wicked Problem. At mid-term elections new House of Representatives and Delegates can be elected for two-year terms, and new Senators for six-year terms. Some are re-elected, but even partial turnovers in committee membership can change the voting balance, and influence appropriation outcomes when combined with the dynamics of national politics, and perceived national budgetary priorities. NASA's budget is below $0.5 \%$ of the national budget and it is in the discretionary funding category, which means that it can be adjusted based on other national or regional priorities. Thus, the appropriated budget can include earmarks, which are specified changes or added constraints to the PBR. These earmarks are often spatially aligned with the Congressmen's regional interests to bring resources to their home states. Depending on local economies, the importance of space related investment and jobs vary between states, translating to earmark-based resource distributions. Depending on the balance between congressional party affiliations, and that of the President (elected every four years), the appropriation committees could either support, oppose, and/or modify the PBR. All of these can result in budgetary uncertainties and instabilities for NASA's appropriation process and outcomes, including continuous re-planning cycles, project de-scopes, delayed milestones and missed deliverables. These have a significant impact on technology development and related strategies. Consequently, we have extended Rittel and Webber's model [Rittel \& Webber, 1973] and termed it: NASA's temporally and spatially coupled cyclical Wicked Problem. Understanding the influences to this Wicked Problem at various levels could help identifying areas where design, design thinking, designerly thinking could be leveraged for strategic decision making at both micro scales (for project and programs) and macro scales (for mission directorates and the Agency).

\section{III.III Strategic Considerations}

As an example, NASA's Office of the Chief Technologist was established 4 years ago, after identifying the need for a protected and self contained entity focusing on the development of future transformational space technologies for the Agency and the Nation. The office was envisioned with an annual budget of 1 billion dollars, and a matching workforce of about 900 civil servants. In 2013 the Office was divided into a small office for the Chief Technologist, addressing Agency-wide policies and strategies, while the majority of the resources was allocated to the Space Technology Mission Directorate. However, the initially requested annual funding level never materialized, and after these years it is about $\$ 576 \mathrm{M}$ in FY14, yet with approximately the same original civil servant complement, which is overly high for the current funding level. This limits procurement for competed new technology projects, and requires hard choices about how resources are allocated. For this type of organization a desired portfolio balance would include 
projects targeting both explorational (or transformational) and exploitational (or incremental) technologies. The former would open up new approaches for the next generation of missions, while the latter would support existing near term stakeholder needs both within the Agency and for the nation. However, the constraints may require to assess original assumptions, reflect current performance, and seek out new opportunities and threats, and by asking questions along the line of:

- Is the current portfolio addresses the appropriate needs?

- Is the organization developing the right technologies, to the right stakeholders, for the right infusion timeframe?

- Can the budget support funding all technology areas identified in the Space Technology Roadmap? If not, where should the focus be?

- Can the budget support developments across all Technology Readiness Levels, from early stage to flight development?

- Can the budget support technology development both inside and outside of NASA?

- Should the investment be near term focused with incremental technologies, or far term focused with more transformational technologies? What is the right balance between the two types of investments?

- How to infuse new transformational technologies into stakeholder needs?

- How to deal with non-performing projects? Would cancellation be warranted to free up resources?

- How to best communicate strategies, related to technology development activities, to key stakeholders and to the broad community? What is the best organizational structure to achieve a desired outcome?

- How to customize the message to various stakeholders - e.g., at various levels from projects to the Agency, to the funding sources of the government, to external companies, to academia, and to the public while being consistent yet maximizing the knowledge transfer?

- How to motivate members of the organization, and how to leverage their talents?

- What are the biggest challenges facing the organization?

- What are the new opportunities and threats that strategies should consider, both short and long term?

- How to overcome innovation barriers, including NASA's risk-averse culture; low priority to innovation; short-term focus; instability; lack of opportunities; process overload; communication challenges; and organizational inertia?

- How to leverage non-traditional approaches, that may not require significant investment yet could greatly enhance project performance, visibility, and awareness both inside and outside of the Agency? For example, NASA's Advance Exploration Systems (AES) under HEOMD worked with the Topcoder community on NASA's Asteroid Grand Challenge, leveraging the skills of the broad code developer community. AES also received 233,431 votes for the new Z-2 spacesuit outer shell design, in effect involving the public at virtually no cost to advertise the technology and design activities of that organization. These strategic approaches can provide added dimensions and resulting benefits to an organization by extending strategic thinking to multiple disciplines beyond linear project and program management lines and practices.

Details and potential approaches to some of these questions can be found in [Balint, 2013].

\section{III.IV Knowledge and Hierarchy}

In his book, Tacit Dimensions [Polanyi, 2009], Polanyi discussed tacit knowledge - opposed to explicit knowledge - which is hard to verbalize or transfer from one person to another. Some refer to it as "fast thinking" [Kahneman, 2013], or "gut feeling." Tacit knowledge can be a great benefit for strategic decision making, as this interconnected set of underlying insights can signal plausible directions even before expressed properly. This knowledge can emerge through a hierarchy where the various levels interface, the same way as sound, words, sentences, and prose build on the top of each other. Through an analogy and redirection, this hierarchy system can be applied to organizations within NASA's framework, building from Project and Program levels, to Mission Directorates, and subsequently to Agency and Government levels (see Figure 5). We consider Project and Program level activities as linear disciplines, driven by highly constrained and goal oriented practices. At these levels engineering and technology drivers address feasibility, while management practices, planning and execution processes deal with viability. The usability aspect, related to Agency or national needs, are driven by higher level strategic considerations. At the Mission Directorate, Agency and Government levels decision making is multi-disciplinary, involving future opportunities, threats, and a broad input from stakeholders, discussed above. The strategies are also hierarchy specific, and can be described as local, regional, and global, respectively. Influences and drivers vary at each level, and coupled through their interfaces (for example between project and program; program and directorate; and so on). In this hierarchical setup, a mismatch between the level and associated drivers can be detrimental to the organization. For example, if the Directorate level focuses too much on Program and Project oversight, it may impact the organization in multiple ways. It spends its resources away from strategic thinking, while forcing the Directorate to operate in a linear discipline mode. Subsequently this may limit the organization's success and competitiveness, especially if contemporary organizations simultaneously leverage their own 


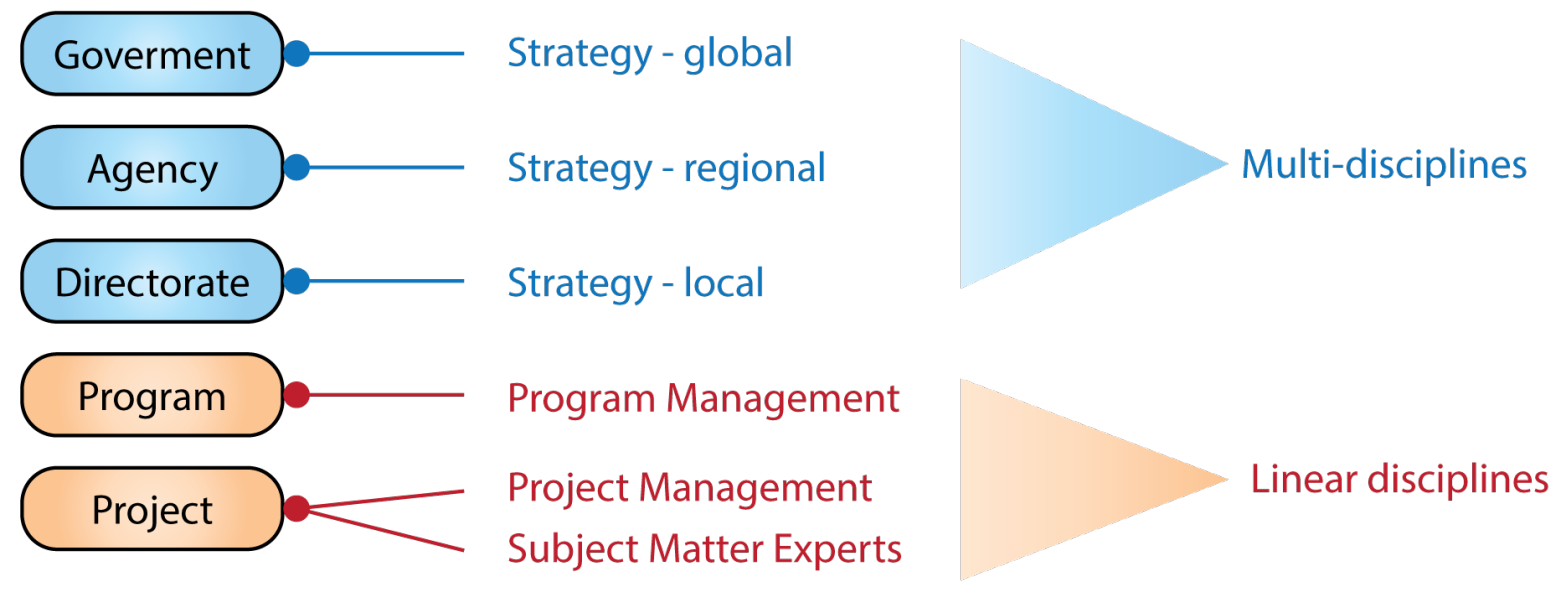

Fig. 5: Notional knowledge hierarchy

strategic advantages. Operating at a lower level also negates the effectiveness, roles and responsibilities of that level, which may propagate through the organization, resulting in reduced effectiveness and lower workplace morale. An organization that is based on planning an execution only, without strategy, feels functional, performing a significant amount of work, but at the same time may go down the wrong path, or spend efforts unnecessarily to cover all bases. For example, performing endless planning exercises instead of having a strategic understanding and narrow the trades to a small but meaningful number of scenarios.

This hierarchy construct can also help to explain the Peter Principle [Peter, 1982], where the selection for a new position is based on the applicant's performance in the current role, instead of the requirements of a new position. At higher levels linear disciplines, such as project management, and program management practices are replaced with strategic thinking, requiring a multi-disciplinary skill set. Strategy is vastly different from planning and execution, especially in engineering and technology fields, which are also considered linear disciplines. Strategy involves assessment and analysis of the situation, identifying options, then setting policies, and combining them with coherent actions [Rumelt, 2011]. Strategic leaders leverage tacit knowledge based on analysis and foresight of multidisciplinary future opportunities and threats, combined with reflections of the ongoing activities and constraints. Design thinking, systems thinking, and integrative thinking, including scenario prototyping can stimulate new ideas, resulting in an emergence of tacit knowledge to communicable knowledge, new options and strategic advantage. This could be further illustrated through Ashby's law of requisite variety (see Figure 6). In order for a system to effectively control another, it must have at least as much variety as the system it is to control, otherwise the control is considered restrictive. As an example, we can look at a thermostat, with an on and off switch. If the temperature is too hot it switches off, and if it too cold, it switches on. The variety of the Regulator is 2 resulting in 2 states for the controlled (Figure 6.a). For a linear discipline field, such as engineering, the variety is tightly controlled, and the disturbance - or the problem to be solved - is filtered by the Regulator's degree of variety, resulting in a well defined outcome (Figure 6.b). Figure 6.c shows a higher level of complexity, which could describe a strategic approach. Without a Regulator, the disturbance propagates through the uncontrolled state to an unchanged outcome. The Regulator imposes its variety to the system, which results options for the controlled set, propagating to an outcome. On one hand, if the Regulator maintains its limited variety, inherited from a linear discipline, the outcomes are over-constrained and controlled down to the same level as that for a linear discipline. While this system produces outcomes, the

(a)

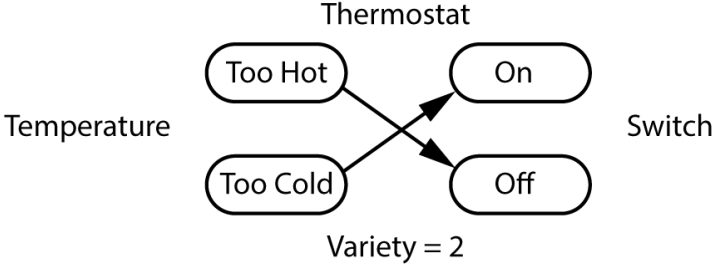

(b)

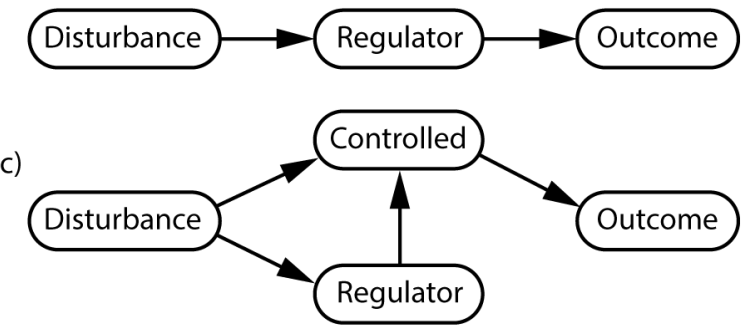

Fig. 6: Ashby's law or requisite variety 
Regulator might not be aware of variety imposed limitations, and the system under-performs and not competitive. If there is too little variety in the controlling system (Regulator), the control becomes restrictive, rather than facilitative. On the other hand, if the Regulator at the strategy level operates with a broadened variety, new options may emerge from the Disturbance, allowing the Regulator the select from a broader set and maximize the success of the outcome. Thus if we want proper enabling control - not restrictive - we must have sufficient variety. In other words, the approach that makes a manager successful in a linear discipline, is not sufficient to be successful at a strategic level. Without adjustment, the success of the organization can be adversely impacted. (The theorem of a good regulator was conceived by Roger C. Conant and W. Ross Ashby [Conant \& Ashby, 1970], and considered central to cybernetics.)

\section{SUMMARY AND CONCLUSIONS}

In this paper we highlighted the complexities associated with NASA's operational and budgetary framework in the government environment; accounted for a broad range of factors, drivers, and constraints at various levels of the organizational hierarchy. The model of Wicked Problems was found to be useful to describe these connections. Based on the findings, we have extended the Wicked Problems model by including key constraints relevant to NASA, and termed it: NASA's temporally and spatially coupled cyclical Wicked Problem.

Wicked Problems are solved through stakeholders, by identifying and negotiating goals, and actions to reach them. Such process of deliberation and argumentation is political. Consequently, technology development at NASA is political, beyond the scope of cost, schedule and performance drivers, and highly influenced by interactions with higher level stakeholders. External stakeholders often have different or loosely coupled drivers connecting to space exploration.

We have demonstrated that the success and even the existence of projects and programs are often dependent on a large number of influencing factors and considerations beyond need (usability), technical feasibility, and fiscal viability. Grasping this framework beyond the bounds of NASA could help strategic decision making, especially in the problem diagnosis phase. It may also provide an insight for project and program managers, who are typically involved with only a subset of this framework.

We have argued that the organizational hierarchy operates through linear disciplines at the project and program levels, and use local, regional, and global strategies at the Mission Directorate, Agency, and Government levels. The required managerial and leadership skill-sets differ between programmatic and strategic levels, influencing the operations and success of an organization.
It is often asked: "why can't NASA decide on an exploration target, may it be the Moon, Mars, an Asteroid or a Lagrangian Point?" This paper may provide the answer. It requires long term policy and strategy commitments from the government, supported by continuing funding for decades at a significantly higher level than NASA's current budget allocation. For NASA, space exploration is driven by scientific and human exploration goals to answer questions about the origin and evolution of our universe, the origin and evolution of life in it, and identifying hazards and resources for humanity. For the government the science and exploration goals are overshadowed by national and international prestige, national priorities, election cycles, short term planning, party politics and other drivers. Without a clear commitment, NASA's best choice is to work on evolvable plans with common underlying technologies and mission architectures, which advance the state of the art, and can be ready on short notice, as soon as an appropriate level of commitment and long term funding support is provided by the government.

\section{FUTURE DIRECTIONS}

Problem definition comes from a specific point of view, and defining the problem inherently defines the solution. Over-constrained problem definition leads to incremental advancements, but not to innovation. Future space exploration missions are highly reliant on transformational space technologies and linked mission architectures. How to overcome this gap? Approaching technology development throughout the eyes of a design thinker can be an answer. Design is a creative approach to problem solving with the power to tackle complex multi-disciplinary and pressing social issues. In comparison, linear disciplines, like engineering, tend to downplay the benefits of design. This might be true at the linear project and program levels, but strategy needs design and design needs strategic considerations. Successful strategies build on design thinking, systems thinking, and integrative thinking, and can help to overcome NASA's innovation barriers.

Today's most innovative technology companies utilize the combination of 1) design thinking, to identify and solve the correct problem; 2) systems thinking, to address the multi-disciplinary nature of the problem; 3 ) integrative design, where practice and theory are blended; and 4) human-centered design, where the users work synergistically with the technology. For these companies, Design is not limited to engineering and business, but used and an all-encompassing approach, which also includes social sciences and the arts. NASA could benefit from these approaches.

Design thinking is typically practice based, and closely aligned with the management framework. In comparison, design practice and theory is described through designerly thinking. [Johansson-Sköldberg, et al., 2013]. In the next phase of this research, we will build on NASA's Wicked Problem framework, 
described in this paper and on the innovation framework in the government environment, discussed in [Balint, 2013]. We will assess the benefits, applicability, and potential implementation approaches of design thinking and designerly thinking within NASA, and potentially at other national space agencies. The assessment will include their applicability for strategic decision making and sense making; for communication and knowledge transfer; for interdisciplinary design processes (e.g., for mission architectures, and systems thinking); for creating and improving design spaces (e.g., innovation foundries, creative spaces, maker labs); for artifact creation (e.g., innovative technology development, and sense giving); and for organizational and management design.

\section{ACKNOWLEDGEMENTS}

The authors wish to thank Stacey Brooks for providing constructive feedback on the paper.

\section{REFERENCES}

Balint, T., 2013. "Disruptive Innovation: A Comparison Between Government and Commercial Space", 64th International Astronautical Congress, Beijing, China, IAC-13-D1.3.3, October

Box, G.E.P., Draper, N.R., 1987. "Empirical ModelBuilding and Response Surfaces", Wiley Series in Probability and Statistics, ISBN-10: 0471810339, ISBN-13: 978-0471810339

Conant, R.C., Ashby, W.R., 1970. "Every good regulator of a system mush be a model of that system", International Journal of Systems Science, , Vol. 1, No. 2, 89-97

Conklin, J., 2006. "Dialogue mapping : building shared understanding of wicked problems", Chichester, England: Wiley Publishing. ISBN 0470017686.

HoR, 2014. "FY15 budget charts", Committee on the Budget, House of Representatives, Viewed on May 4, 2014, Website: http://budget.house.gov/ uploadedfiles/fy15_budget_charts.pdf

Johansson-Sköldberg, U., Woodilla, J., Çetinkaya, M., 2013. "Design Thinking: Past, Present and Possible Futures", Creativity an Innovation Management, Vol.22, No.2, John Wiley \& Sons Ltd.

Kahneman, D., 2013. "Thinking, Fast and Slow", Farrar, Straus and Giroux; Reprint edition, ISBN-13: 978-0374533557

NASA, 2014. "FY15 Mission Directorate Fact Sheets", National Aeronautics and Space Administration, Viewed on May 4, 2014, Website: http:// www.nasa.gov/sites/default/files/files/ FY15_MD_Fact_Sheets.pdf
NASA-STMD, 2014. "NASA Fiscal Year 2013, Space Technology Budget", National Aeronautics and Space Administration, Viewed on May 4, 2014, Website: http://www.nasa.gov/sites/default/files/ 632690main NASA FY13 Budget SpaceTech-508.pdf

Norman, D., Klemmner, S., 2014. "State of Design: How design education must change", Website: http://www.linkedin.com/today/post/article/ 20140325102438-12181762-state-of-design-howdesign-education-must-change?trk $=$ mp-reader-card, Published on: March 25, Viewed on April 14, 2014.

Peter, L.J., 1982. "Peter's Almanac", William Morrow \& Co., ISBN-13: 978-0688016128

Polanyi, M., 2009. "The Tacit Dimension", University Of Chicago Press; Reissue edition (May 1, 2009), ISBN-13: 978-0226672984

Rittel, H.W.J., Webber, M.M., 1973. "Dilemmas in a General Theory of Planning", Policy Sciences 4, pp.155-169, Elsevier Scientific Publishing Company, Amsterdam

Roberts, N.C. "Wicked Problems and Network Approaches to Resolution.," The International Public Management Review., Vol. 1, 1 (2000).

Rumelt, R.P., 2011. "Good Strategy, Bad Strategy - the Difference and Why It Matters", Crown Publishing Group, Random House, New York, eISBN: 978-0-307-88625-5

Stevens, J., 2013. "Design as communication in microstrategy — strategic sensemaking and sensegiving mediated through designed artefacts", Artificial Intelligence for Engineering Design, Analysis and Manufacturing, vol.27, pp.119-128, Cambridge University Press, doi:10.1017/S0890060413000036

Weinberg, G.M., 1991."The Simplification of Science and the Science of Simplification",in "Facets of Systems Science", ed. Klir, G.J., International Federation for Systems Research International Series on Systems Science and Engineering Vol.7, p p $501-505$, S p ringer US, d o i : 10.1007/978-1-4899-0718-9_35 